\title{
Survivin inhibitor YM155 suppresses gastric cancer xenograft growth in mice without affecting normal tissues
}

\author{
Xiao Jiao Cheng ${ }^{1}$, Jia Cheng Lin ${ }^{1}$, Yan Fei Ding ${ }^{2}$, Liming Zhu ${ }^{1}$, Jing $\mathrm{Ye}^{3}$ and Shui \\ Ping Tu ${ }^{1}$ \\ 1 Department of Oncology, Renji Hospital, School of Medicine, Shanghai Jiaotong University, Shanghai, China \\ 2 Department of Gastroenterology, Ruijin Hospital, School of Medicine, Shanghai Jiaotong University, Shanghai, China \\ 3 Pôle Sino-Français de Recherches en Sciences du Vivant et Génomique, Ruijin Hospital, School of Medicine, Shanghai \\ Jiaotong University, Shanghai, China \\ Correspondence to: Shui Ping Tu, email: tushuiping@yahoo.com \\ Keywords: YM155, survivin, gastric cancer, xancer stem cells, cancer therapy \\ Received: September 04, 2015 Accepted: December 31,2015 Published: January 12, 2016
}

\section{ABSTRACT}

Survivin overexpression is associated with poor prognosis of human gastric cancer, and is a target for gastric cancer therapy. YM155 is originally identified as a specific inhibitor of survivin. In this study, we investigated the antitumor effect of YM155 on human gastric cancer. Our results showed that YM155 treatment significantly inhibited cell proliferation, reduced colony formation and induced apoptosis of gastric cancer cells in a dose-dependent manner. Accordingly, YM155 treatment significantly decreased survivin expression without affecting XIAP expression and increased the cleavage of apoptosis-associated proteins caspase 3, 7, 8, 9. YM155 significantly inhibited sphere formation of gastric cancer cells, suppressed expansion and growth of the formed spheres (cancer stem cell-like cells, CSCs) and downregulated the protein levels of $\beta$-catenin, c-Myc, Cyclin D1 and CD44 in gastric cancer cells. YM155 infusion at $5 \mathrm{mg} / \mathrm{kg} /$ day for 7 days markedly inhibited growth of gastric cancer xenograft in a nude mouse model. Immunohistochemistry staining and Western Blot showed that YM155 treatment inhibited expression of survivin and CD44, induced apoptosis and reduced CD44+ $C S C s$ in xenograft tumor tissues in vivo. No obvious pathological changes were observed in organs (e.g. heart, liver, lung and kidney) in YM155-treated mice. Our results demonstrated that YM155 inhibits cell proliferation, induces cell apoptosis, reduces cancer stem cell expansion, and inhibits xenograft tumor growth in gastric cancer cells. Our results elucidate a new mechanism by which YM155 inhibits gastric cancer growth by inhibition of CSCs. YM155 may be a promising agent for gastric cancer treatment.

\section{INTRODUCTION}

Gastric cancer is one of the world's most common malignancies. Although diagnosis and treatment of gastric cancers have been greatly improved, the overall survival rate remains low. Less than $20 \%$ of patients with gastric cancer survive to 5 years [1]. Survivin, a member of inhibitor apoptosis (IAP) protein family, is implicated in both cell survival and regulation of mitosis in cancer cells $[2,3]$. Survivin is expressed in various primary tumors, but is rare expressed in normal differentiated tissues [4]. Previous studies showed that an over expression of survivin is found in human gastric cancer tissues, and is a poor prognostic factor in gastric cancer patients [5-7].
Moreover, overexpression of survivin is detected in gastric cancer cells during drug treatment, indicating that survivin may contribute to chemo-resistance in gastric cancer [810]

Recent studies showed that survivin is also associated with cancer stem cells (CSCs). Survivin has been demonstrated to be a downstream gene of the Wnt signal pathway and is highly expressed in colon cancer stem cells [11]. Wnt $/ \beta$-catenin signaling has also been demonstrated to be essential for the proliferation of gastric CSCs $[12,13]$. Zhang et al. found that mutant APC upregulates survivin, causing apoptosis inhibition and the expansion of colon tissue stem cells in the colon crypt, thereby initiating colon tumorigenesis $[14,15]$. Carter 
et al. showed that survivin is overexpressed in AML stem/progenitor cells [16]. These results suggest that survivin is a potential target for inhibiting cancer stem cells proliferation. Whether YM155 downregulates other target genes of CSC signaling such as $\beta$-catenin, c-Myc, Cyclin D1 and CD44 remains unknown. CD44 has been demonstrated to be a marker of human gastric cancer CSC and $\mathrm{CD} 44^{+}$gastric cancer cells have stronger tumorigenic than CD44- gastric cancer cells $[17,18]$. However, whether YM155 inhibits gastric CSCs remains to be investigated.

Several approaches have been developed to target inhibition of survivin for cancer therapy. Those approaches include, administering a molecular antagonist to target survivin mRNA and to inhibit survivin translation (including antisense oligonucleotides, ribozymes and small interfering RNAs), utilizing gene therapy approaches grounded on the use of survivin dominant-negative mutants (Cys84Ala, Thr34Ala) and the application of the survivin promoter to drive the expression of cytotoxic genes; survivin-based immunotherapy; small-molecule antagonists (suppressing survivin function) [19]. Considerable effects have also been made to target inhibition of survivin for gastric cancer therapy. For example, RNAi-mediated survivin knockdown can effectively inhibit the growth of gastric cancer cells $[20,21]$. Our previous studies have shown that suppression of survivin expression or function by plasmid vectors encoding antisense survivin or survivin dominantnegative (DN) mutant (Cys84Ala) can inhibit gastric cancer carcinogenesis and angiogenesis in vivo [22]. While those approaches are effective, it is still difficult to use in clinic. Recent studies showed that YM155, a novel small, imidazolium-based compound can specifically inhibit survivin expression and induce apoptosis in human cancer cells [23]. Preclinical studies demonstrated that three to seven-day continuous infusion of YM155 (1-10mg/kg.d) significantly inhibited tumor growth in hormone-refractory prostate cancer, melanoma and non-small-cell lung cancer [24]. Moreover, recent results from completed phase I/II clinical studies show that YM155 was safe at a dose of $4.8 \mathrm{mg} / \mathrm{m}^{2} /$ day for 168 hours every 3 weeks and exhibited encouraging anti-cancer effect in advanced cancer patients [25-29]. These results suggest that YM155 is a promising agent for cancer therapy.

However, there are no studies to show that YM155 inhibit gastric tumor growth in vivo. In this study, we have evaluated the antitumor effect of YM155 in gastric cancer cell lines. We found that YM155 induced apoptosis of gastric cancer cells, inhibited expansion of gastric CSCs and expression of CSC molecules CD44 and $\beta$-catanin and suppressed gastric cancer xenograft growth. Our results, for the first time, demonstrate that YM155 inhibits gastric cancer growth by inhibition expansion of CSCs and document a new mechanism that YM155 inhibits tumor growth.

\section{RESULTS}

\section{YM15 inhibits cell proliferation in gastric cancer cells}

To investigate the effect of YM155 on cell proliferation of gastric cancer cells in vitro, gastric cancer SGC-7901 and MKN-28 cells were treated with YM155 for 48 hours; cell proliferation was measured by MTT. The results showed that YM155 significantly inhibited cell proliferation. The mean IC50 of SGC-7901 and MKN-28 cells were $13.2 \mathrm{nM}$ and $11.6 \mathrm{nM}$ (Figure 1A), respectively. YM155 has also shown a great activity against other gastric cancer cell lines, such as AGS and Hs 764T cell lines, with IC50 values $0.8 \mathrm{nM}$ and $7.3 \mathrm{nM}$ [24].

To further investigated the effect of YM155 on cell transformation. Soft agar assay was conducted to determine cell transformation in vitro. The result showed that gastric cancer SGC-7901 cells treated with YM155 formed less number of colonies and smaller size colonies in soft agar compared to control cells treated with DMSO (Figure 1B, upper panel). Same results were obtained in AGS cells (Figure 1B, bottom panel). Quantification analysis showed that YM155 treatment significantly inhibited colony formation in gastric cancer SGC-7901 and AGS cells in a dose-dependent manner (Figure 1C). The rates of colony formation in SGC-7901 were reduced by $55.7 \%$ and $86.9 \%$ at dose of $5 \mathrm{nM}$ and $10 \mathrm{nM}$ of YM155, respectively. Similar results were obtained in AGS cells. YM155 at $5 \mathrm{nM}$ and $10 \mathrm{nM}$ reduced colony formation of AGS cells by $28.9 \%$ and $50.3 \%$, respectively, compared with control DMSO treatment. These results suggest that YM155 inhibits anchored-dependent and anchored-independent growth of gastric cancer cells.

\section{YM155 induces apoptosis of gastric cancer cells}

To investigate the effect of YM155 on apoptosis of gastric cancer cells, we first determined the effect of YM155 on survivin expression. The results showed that YM155 effectively inhibited mRNA expression of survivin in SGC-7901 and MKN-28 cells in a dosedependent manner (Figure 2A). FACS analysis showed that YM155 induced apoptosis of SGC-7901 (Figure 2B) in a dose-dependent manner. Quantification analysis showed that apoptosis rates were significantly increased in YM155-treated gastric cancer cells compared to the control groups (Figure 2C), the apoptosis rates were 47.6 $\pm 2.9 \%$ and $82.4 \pm 3.4 \%$ when SGC-7901 cells treated by YM155 at the doses of $10 \mathrm{nM}$ and $20 \mathrm{nM}$ YM155 for 24 hours, respectively. The apoptosis rate of control group was only $6.2 \pm 0.2 \%$. Same results were obtained in AGS cells (Figure 2D). The results demonstrate that YM155 induce apoptosis of gastric cancer cells efficiently. 


\section{YM155 induces apoptosis by activating intrinsic and extrinsic apoptotic pathways}

To investigate the underlying mechanisms by which YM155 induces apoptosis in gastric cancer cells, we determined the effect of YM155 on caspases signaling. Western Blot showed that YM155 could decrease protein level of survivin in a dose-dependent manner without affecting the level of XIAP (Figure 3A). Accordingly, YM155 treatment significantly increased the cleavage of effector caspases such as caspase-3, caspase-7, and
PARP (the substrate of caspases 3). Furthermore, YM155 treatment could increase the cleavage of both caspase-9 and caspase- 8 , which are involved in intrinsic and extrinsic apoptosis signal pathways, respectively (Figure 3A).

To further confirm whether YM155 induces apoptosis through activation of intrinsic and extrinsic apoptosis pathways, we tested the effects of caspase- 8 and caspase-9 inhibitors on YM155-induced apoptosis. TUNEL results showed that pre-treatment with caspase-8 inhibitor Z-IETD-FMK (20 M) or caspase-9 inhibitor Z-LEHD-FMK $(20 \mu \mathrm{M})$ for 1 hour significantly decreased YM155-induced apoptosis of SGC-7901 cells (Figure 3B).
A

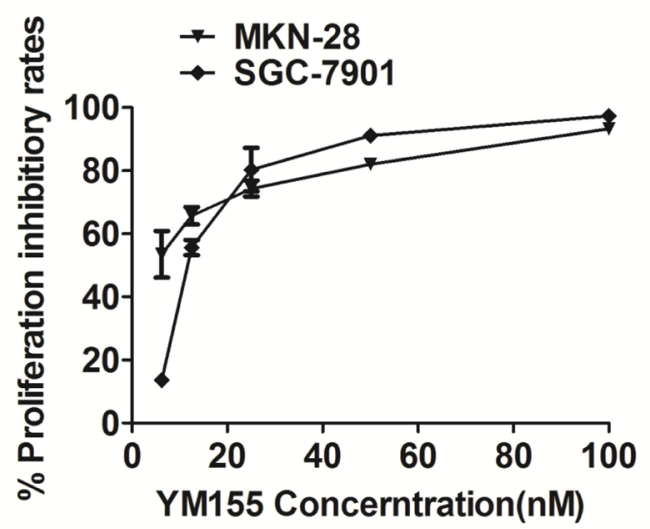

\section{C}

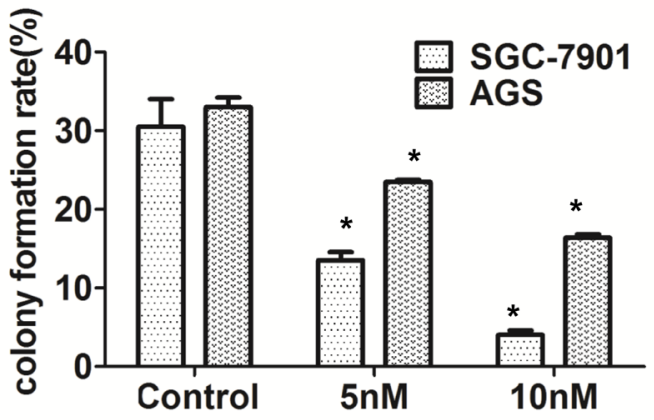

B

Control
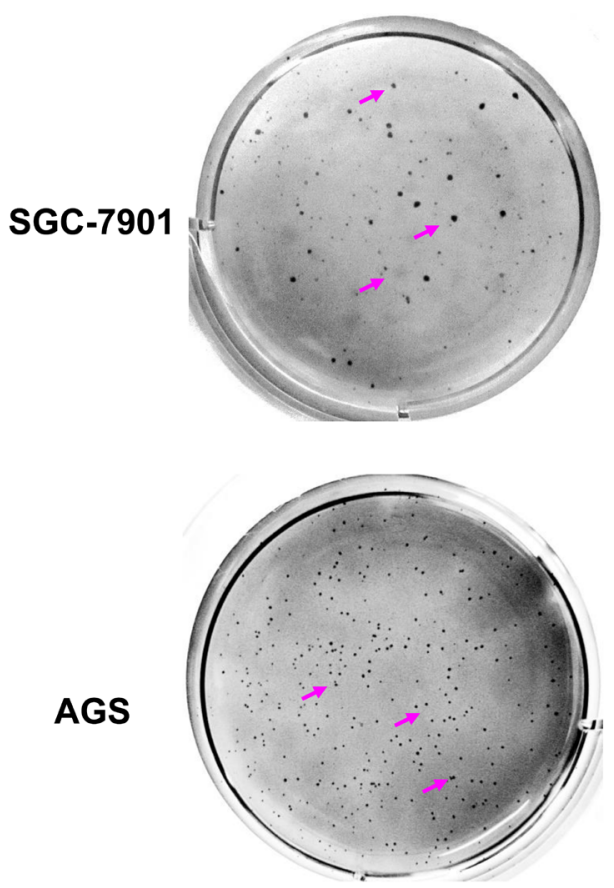

YM155 (5 nM)
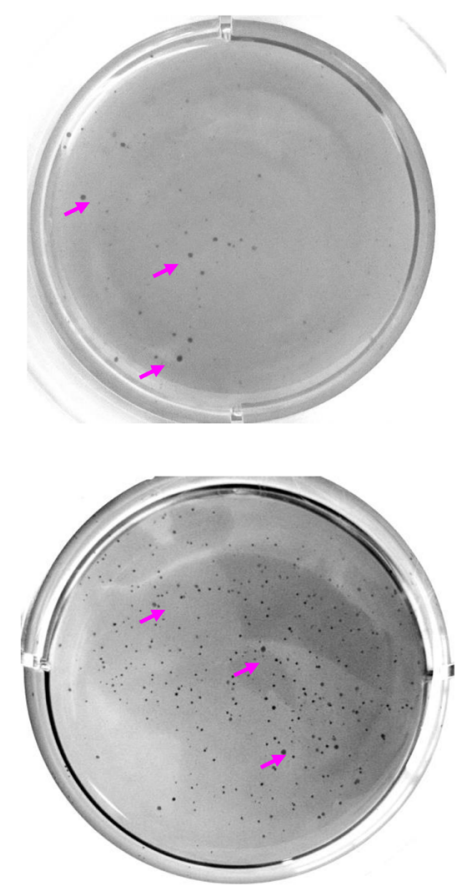

YM155 (10 nM)
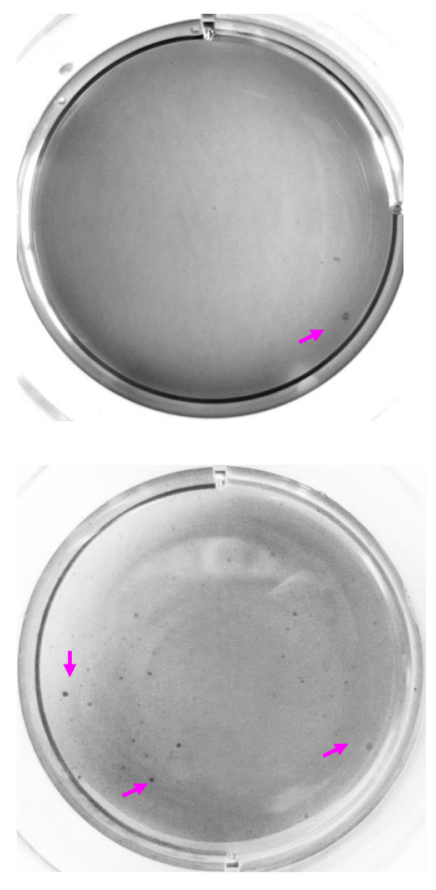

Figure 1: YM155 inhibits anchored-dependent and anchored-independent growth in gastric cancer cells. A. YM155 inhibits cell proliferation of gastric cancer cells. MKN-28 and SGC-7901 cells were cultured in 96-well plates and treated with YM155 at indicated doses. Cell proliferation was detected by MTT method. The data presented is means \pm SD of 3 independent experiments. B. YM155 inhibits the colony formation of gastric cancer cells. Colonies in soft agar assay were stained with $0.1 \%$ crystal violet at 16 days after culture. Representative colonies were photographed. Arrows indicate colonies formed in soft agar. C. The number of colonies in $\mathbf{B}$. was counted under microscope. Data represented is the means $\pm \mathrm{SD}$ of three independent experiments. ${ }^{*} P<0.05$ compared with the control group. 
Quantification analysis showed that the apoptosis rate of SGC-7901 cells in YM155 treated group was 17.2\% \pm $7.2 \%$, while pretreated with $20 \mathrm{M}$ caspase- 8 inhibitor or caspase- 9 inhibitor for 1 hour, the apoptosis rates of SGC7901 cells were $4.9 \% \pm 1.8 \%$ and $5.2 \pm 1.4 \%$, respectively (Figure 3C), suggesting that caspase-8 and caspase-9 inhibitors inhibit YM155-induced apoptosis. These results demonstrate that YM155 induced apoptosis by triggering intrinsic and extrinsic apoptotic pathways.

\section{YM155 inhibits stem-like sphere formation}

Overexpression of survivin has been shown to be associated with CSCs. Hypothesized that YM155 can suppress gastric CSCs by inhibition of survivin. Several approaches have been developed to evaluate CSCs [3032]. One approach is to use a in vitro method, "spheroid colony formation", that candidate CSCs were cultured in serum-free medium containing only EGF and bFGF (stem cell medium, SCM) using a ultra-low-attachment plates. We first investigated the effect of YM155 on sphere formation. SGC-7901 cells and AGS cells were cultured in SCM with and without YM155 for 2 weeks. Quantification analysis of spheres showed that YM155 reatment significantly reduced spheres formation in SGC7901 and AGS cells in dose dependent patterns (Figure 4A). These results indicate that YM155 can inhibit formation of spheres in gastric cancer cells. To determine whether YM155 also reduces expansion of gastric CSCs, SGC-7901 cells were first cultured in SCM for one week to form sphere. One week after culturing, SGC-7901 cells formed small spheroid colonies (spheres) (Figure 4B, upper panel). These formed spheres of SGC-7901 cells were then treated with YM155 at the doses of $1 \mathrm{nM}, 10$ $\mathrm{nM}$ and $20 \mathrm{nM}$ in SCM for one more week. We observed that vehicle-treated spheres greatly expanded and formed large size colonies, and that YM155-treated spheres grew slowly, and formed smaller size colonies compared to vehicle-treated spheres (Figure 4B, bottom panel). The similar inhibition of sphere growth was also observed
A

B
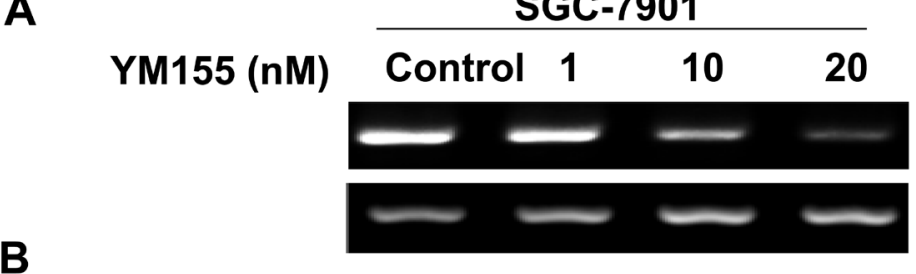

YM155 (nM) Control

1

SGC-7901

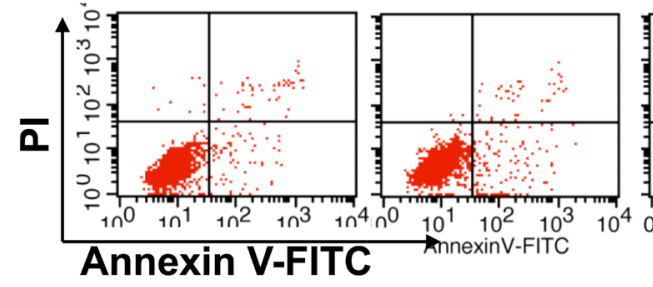

Survivin

GAPDH

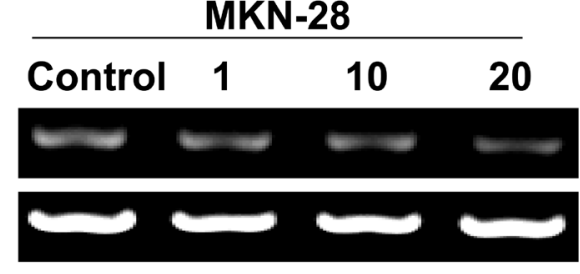

10

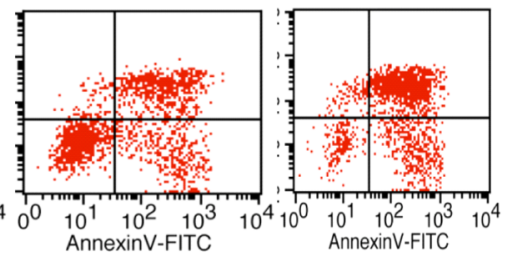

C

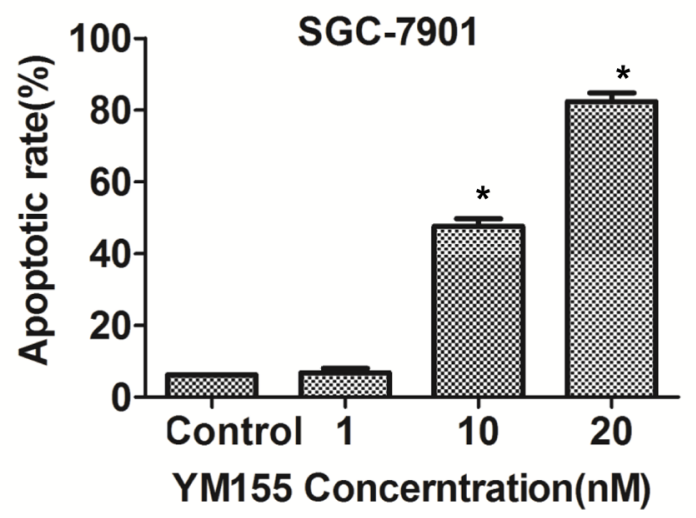

D

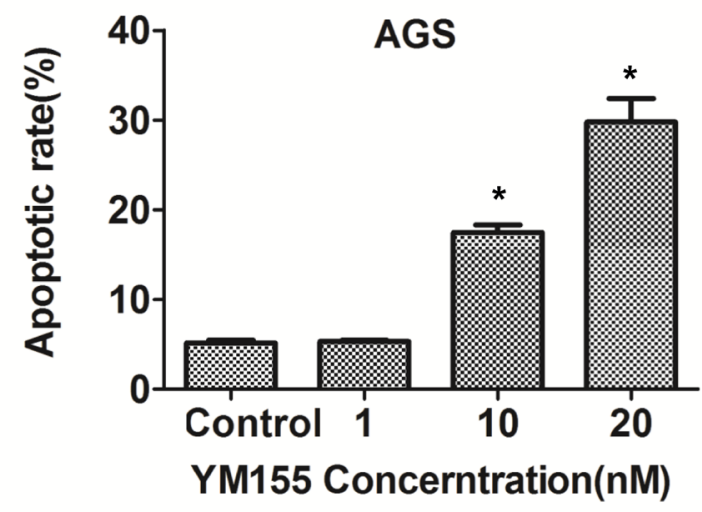

Figure 2: YM155 down-regulates survivin expression and induces apoptosis of gastric cancer cells. A. YM155 inhibits mRNA expression of survivin. SGC-7901 \& MKN-28 cells were treated with YM155 at indicated dose for 24 hours. The mRNA expression of survivin was determined by RT-PCR. B.-D. YM155 induces apoptosis of gastric cancer cells. SGC-7901 cells and AGS cells were treated with YM155 at indicated doses for 24 hours. Apoptosis was determined by FACS analysis. Representative FACS Plots was shown in B. The apoptotic rates are the means $\pm \mathrm{SD}$ of 3 independent experiments $* P<0.05$ compared with the control group. 
in AGS cells treated with YM155 (data not shown). The results suggest that YM155 inhibits expansion of gastric CSCs.

\section{YM155 inhibits expression of CSC molecules}

We then explored the underlying mechanisms by which YM155 inhibits the expansion of gastric CSCs. Since $\mathrm{Wnt} / \beta$-catenin signaling has been demonstrated to be essential for the expansion of gastric CSCs $[12,13]$, we tested the effect of YM155 on Wnt signaling. Western Blot showed that YM155 decreased the level of $\beta$-catenin and the expression of c-Myc and Cyclin D1, which are downstream of $\mathrm{Wnt} / \beta$-catenin signaling (Figure $4 \mathrm{C}$ ). CD44 has been identified as a marker of gastric CSCs [17, 18, 33]. YM155 treatment downregulated expression of CD44 in gastric cancer cells (Figure 4C). These results suggest that YM155 inhibits expansion of gastric CSCs by inhibiting $\mathrm{Wnt} / \beta$-catenin signaling and expression of CD44.

YM155 inhibits growth of gastric cancer
xenograft

We finally investigated the effects of YM155 on tumor growth in a xenograft mouse model. SGC7901 cells were injected into the frank of athymic nude mice to establish tumor xenograft. When tumor size reached around $80 \mathrm{~mm}^{3}-100 \mathrm{~mm}^{3}$, mice received a 7-day continuous infusion of YM155 at $5 \mathrm{mg} / \mathrm{kg} /$ day or vehicle control. The results showed that tumors in the mice treated with YM155 grew slowly compared to tumor in the mice treated with vehicle control (Figure 5A-5B). Tumor

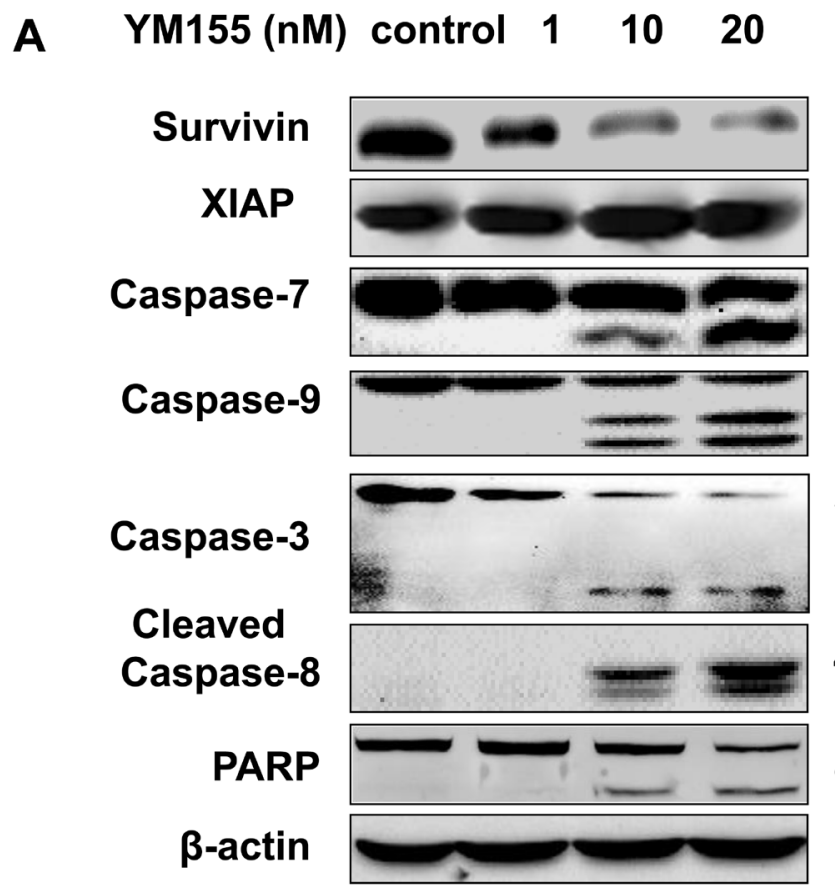

16KDa

35KDa

20KDa

47KDa

37/35KDa

35KDa

19/17KDa

43/41KDa

116KDa

89KDa

C

B

\section{Control}

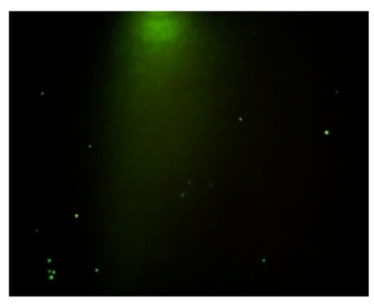

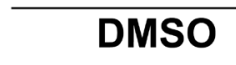

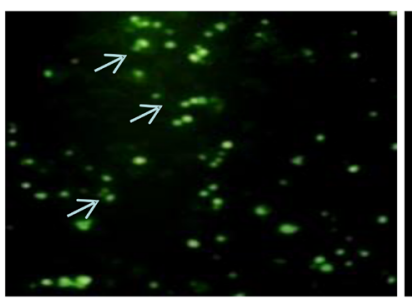

\section{KDa}
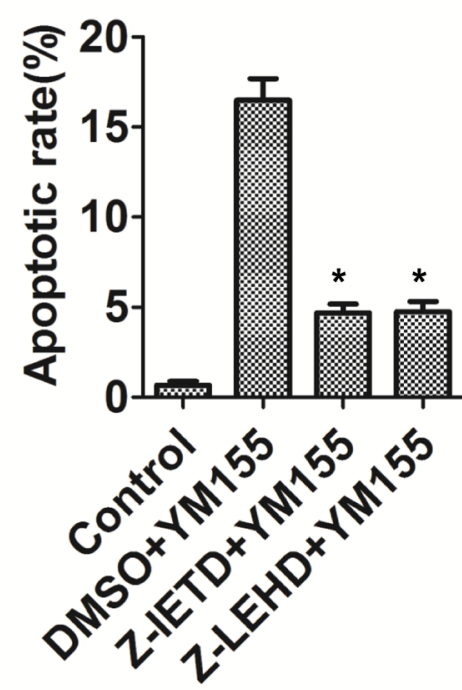

YM155 (20 nM)
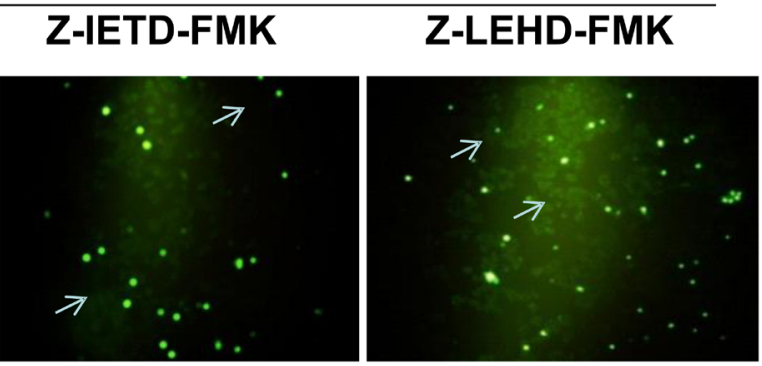

Figure 3: YM155 triggers intrinsic and extrinsic apoptotic pathways. A. YM155 treatment decreased survivin expression without affecting XIAP and induced cleavage of caspases. Protein expression (caspase-3, -7, -9, -8, PARP) was detected by Western Blot analysis. B. Pre-treatment of caspase inhibitors attenuates YM155-induced apoptosis. Gastric cancer cells were pre-treated with $20 \mu \mathrm{M}$ caspase-8 inhibitor (Z-IETD-FMK) or $20 \mu \mathrm{M}$ caspase-9 inhibitor (Z-LEHD-FMK) for 1 hour and treated with YM155 (20 nM) for another 24 hours. Apoptosis was detected by TUNEL assay. Representative photos were taken under fluorescence microscope 24 hours after the YM155 treatment. Arrows indicate apoptotic cells (green cells) $(200 \times)$. C. Quantification of apoptotic cells. The apoptotic rates presented from $\mathbf{B}$. are the means $\pm \mathrm{SD}$ of 3 independent experiments. $* P<0.05$ compared with the control group. 
growth curve showed that YM155 treatment resulted in persistent inhibition of tumor growth and tumor shrank (Figure 5B). Accordingly, YM155 treatment significantly reduced tumor weight compared to the control treatment (Figure 5C). The results demonstrate that YM155 inhibits gastric cancer tumor growth in vivo.

\section{YM155 induces apoptosis and inhibits gastric CSCs in vivo}

To determine whether YM155 inhibits survivin expression in xenograft tissues, tumor tissues were subjected to Western Blot and IHC staining. Western Blot showed that the band densities of survivin protein were lower in the tumor tissues from YM155-treated mice than in those from vehicle-treated mice (Figure 6A, left and middle panel). IHC showed that the intensity of survivin staining in tumor tissues from YM155-treated mice were significantly weaker than in those from vehicle-treated mice (Figure 6B). Quantification analysis showed that the number of survivin ${ }^{+}$staining cells in the tumors from YM155-treated mice were also significantly lower than in those from vehicle-treated mice (Figure 6C). The results suggest that YM155 inhibit survivin expression in vivo.

Accordingly, we found that YM155 treatment increased the number of cleaved caspases-3-positive cells (apoptotic cells) in xenograft tumor tissues compared to control treatment (Figure 6B). Quantification analysis showed that caspase 3 positive rates in the tumor was significantly higher in YM155-treated mice than vehicletreated mice $(2.80 \% \pm 0.11 \%$ vs $1.07 \pm 0.15 \%, p<0.01)$ (Figure 6D). These results indicate that YM155 induces apoptosis of gastric cancer in vivo.

To further explore whether YM155 also inhibits gastric CSCs in vivo we determined expression of CD44

C
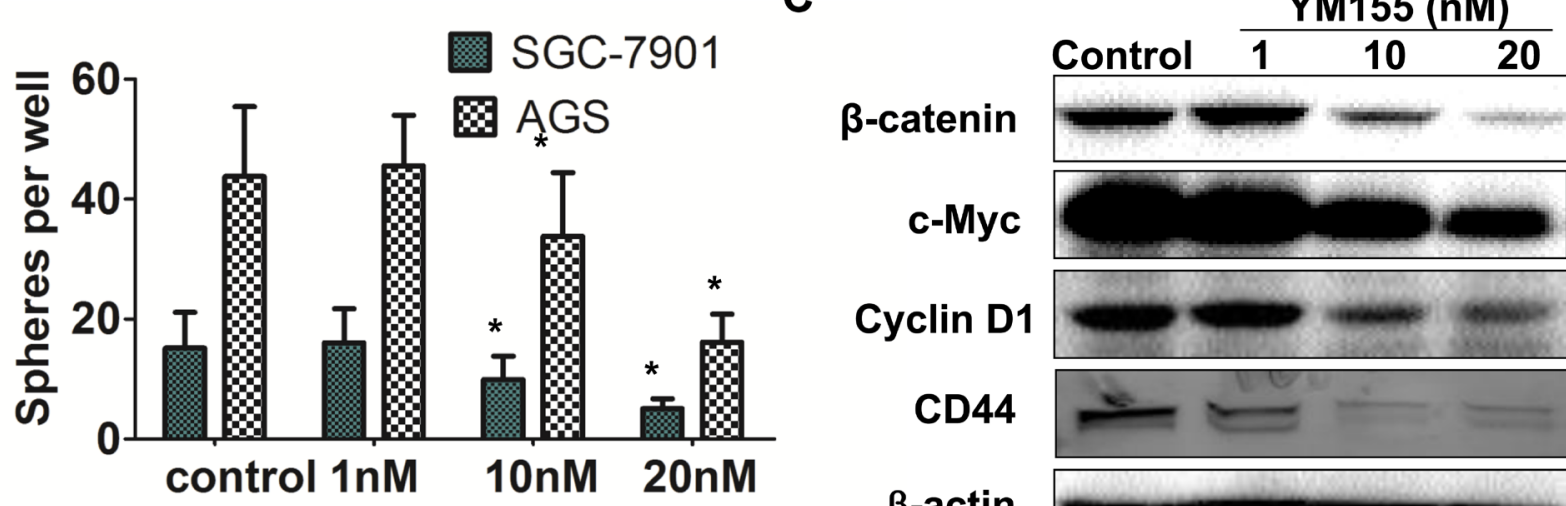

B

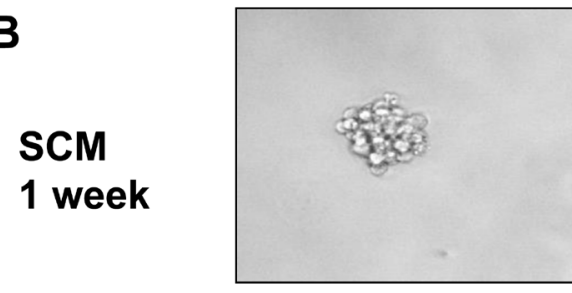

Control

\section{Week after YM155 treatment}

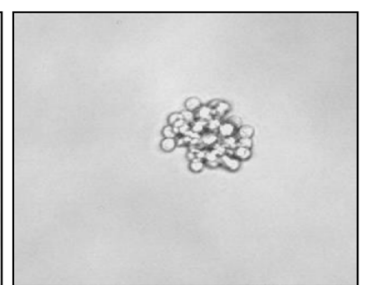

$1 \mathrm{nM}$
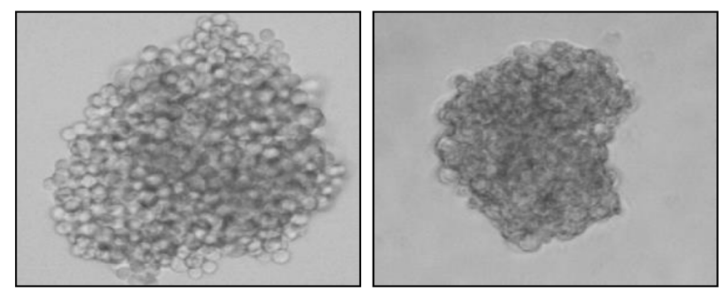

$\beta$-actin

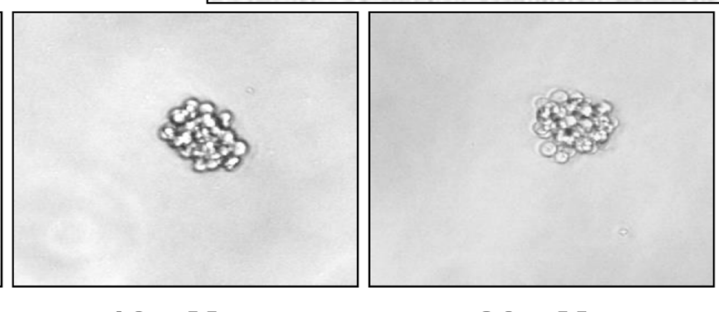

$10 \mathrm{nM}$

$20 \mathrm{nM}$
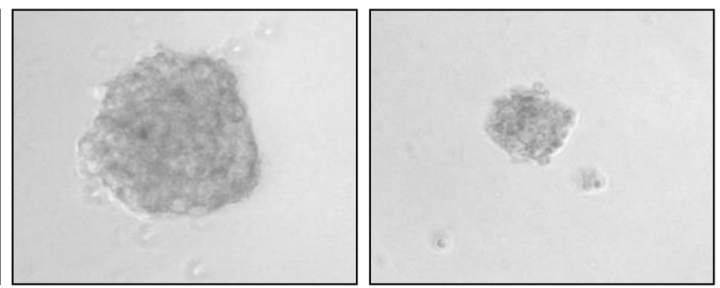

Figure 4: YM155 inhibits formation and expansion of gastric cancer spheres. A. YM155 inhibits sphere formation of gastric cancer cells. SGC-7901 and AGS cells (100 per well) were cultured for 2 weeks in SCM supplement with or without YM155 at indicated doses. The spheres were counted under microscope. The data presented are the means \pm SD of 3 independent experiments.* $P<0.05$ compared with the control group. B. YM155 inhibits expansion of spheres of gastric cancer cells. SGC-7901 cells were cultured for 1 week in SCM to form sphere (upper panel), and then treated with YM155 at indicated doses for another 1 week. YM155 treatment inhibits growth of spheres. Representative photos were taken at one week after the YM155 treatment $(200 \times)$. C. YM155 inhibited expression of CSC molecules. SGC-7901 cells were treated with YM155 at indicated doses for 24 hours. The protein levels of genes were determined by Western Blot. 
in xenograft tissues by Western Blot and IHC staining. Western blot showed that the protein levels (densities of band) of CD44 in the tumors from YM155-treated mice were lower than those in the mice from vehicletreated mice (Figure 6A left and right panel). Although IHC staining showed that the number of $\mathrm{CD}_{4} 4^{+}$staining cells was not significantly different between the groups, the intensity of $\mathrm{CD}_{4} 4^{+}$staining were markedly weaker in tumor tissues from YM155-treated mice compared to those in tumor tissues from vehicle-treated mice (Figure 6B). Quantification analysis showed that the densities of $\mathrm{CD}_{4} 4^{+}$positive staining were significantly lower in the tumor from the YM155-treated mice than those in tumor tissues from vehicle-treated mice (Figure 6E). The results indicate that YM155 reduces CD44 expression and inhibits gastric CSCs in vivo

\section{Assessment of YM155 treatment safety}

We also determined the effects of YM155 on normal tissues. Furthermore, we did not observe obvious pathological change in some organs (heart, liver, lung, and kidney) of YM155-treated mice (Figure 7), suggesting that YM155 treatment is safety in our mouse mice model.

\section{DISCUSSION}

Survivin is highly expressed in the majority of human cancer tissues, including gastric cancer, and is associated with drug-resistance and poor prognosis [34, 35]. Suppression of survivin expression or function resulted in spontaneous apoptosis, increased sensitivity to cytotoxic drugs and suppression of tumor growth in a nude mouse model $[22,36]$. These data indicate that targeted inhibition of survivin is a potential and promising approach for the treatment of gastric cancer [22]. In this study, we further found that YM155, a specific survivin

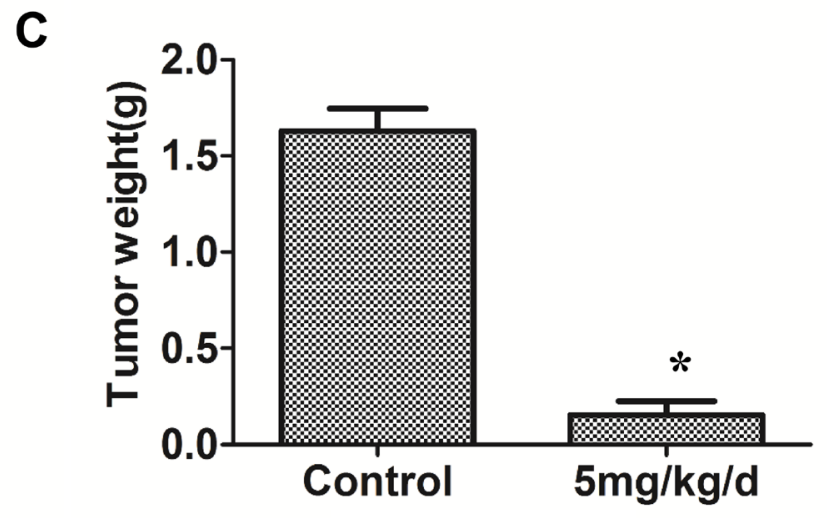

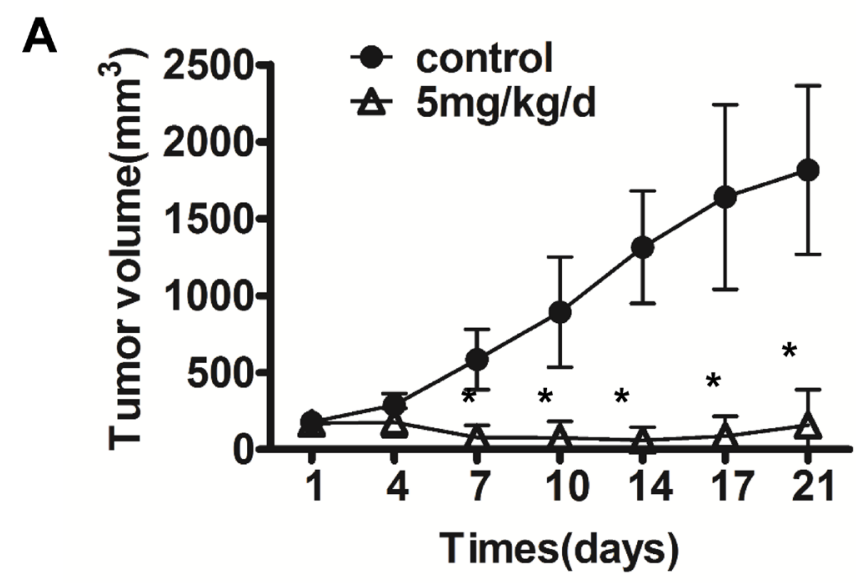

B

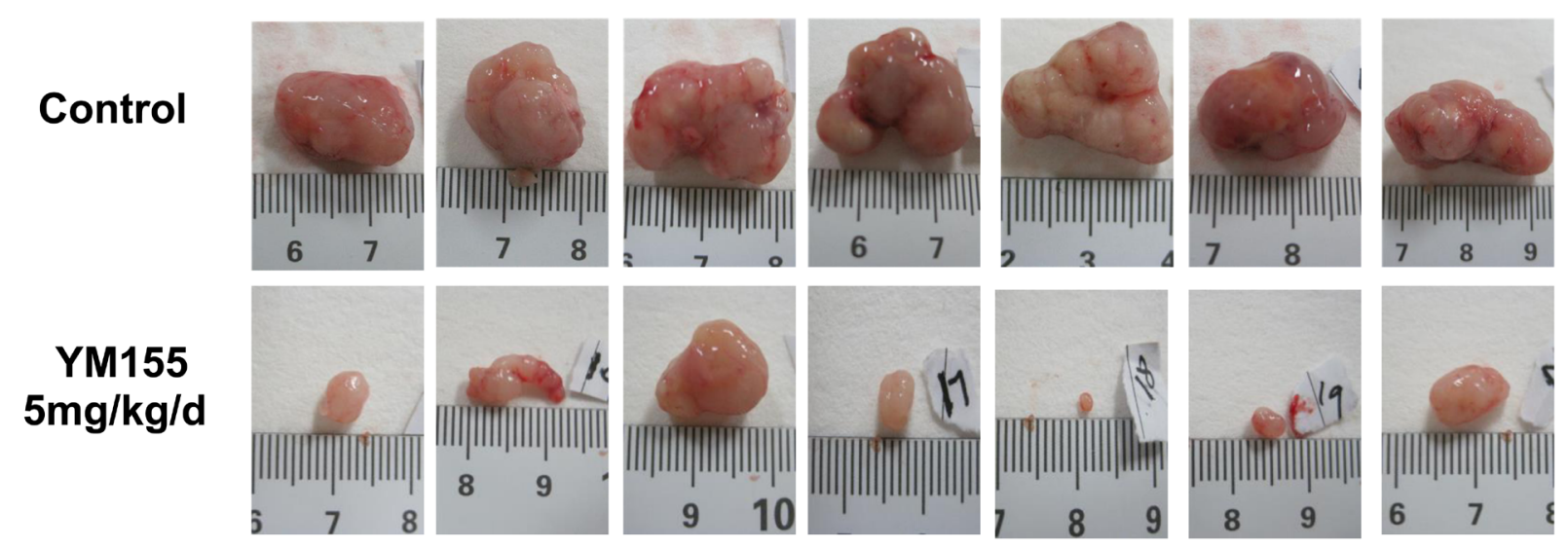

Figure 5: YM155 inhibits xenograft growth of gastric cancer. Tumor xenografts were established by s.c. injection of SGC-7901 cells into the right flanks of the mice $\left(5 \times 10^{6} / 0.1 \mathrm{ml}\right.$ per mouse). When tumor size reached around $80 \mathrm{~mm}^{2}-100 \mathrm{~mm}^{2}$, mice were administered with a 7-day YM155 continuous infusion using a micro-osmotic pump. Tumor size was measured every three days. The tumor growth curve was shown in A. Three weeks after treatment, xenograft tumors were excised and photographed. Representative tumor photos were shown in B. Data presented are the means $\pm \mathrm{SD}$ of tumor weight per mouse $(m=7) \mathbf{C}$. $* P<0.05$ compared with the control group. 

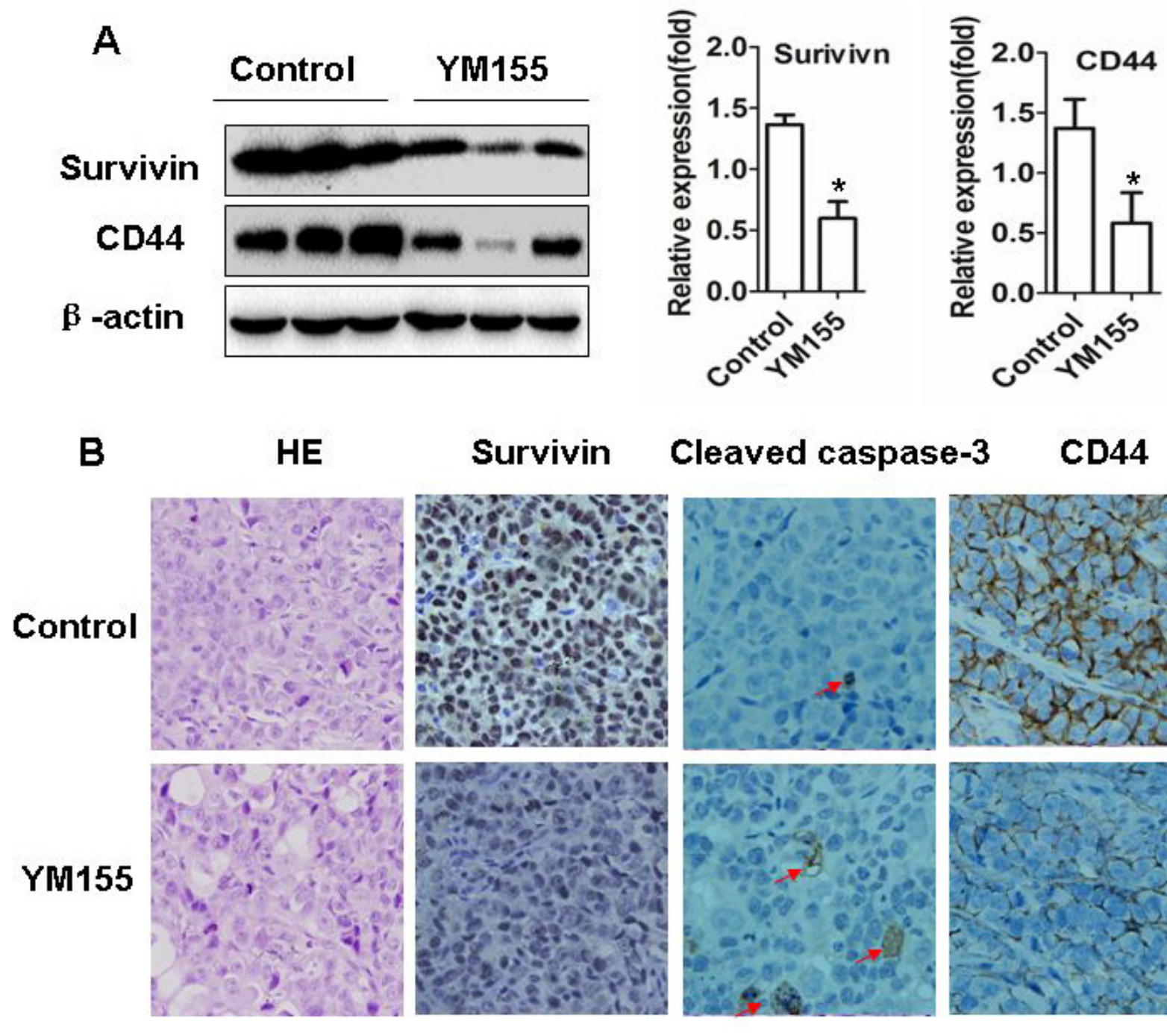

\section{Survivin Cleaved caspase-3 CD44}
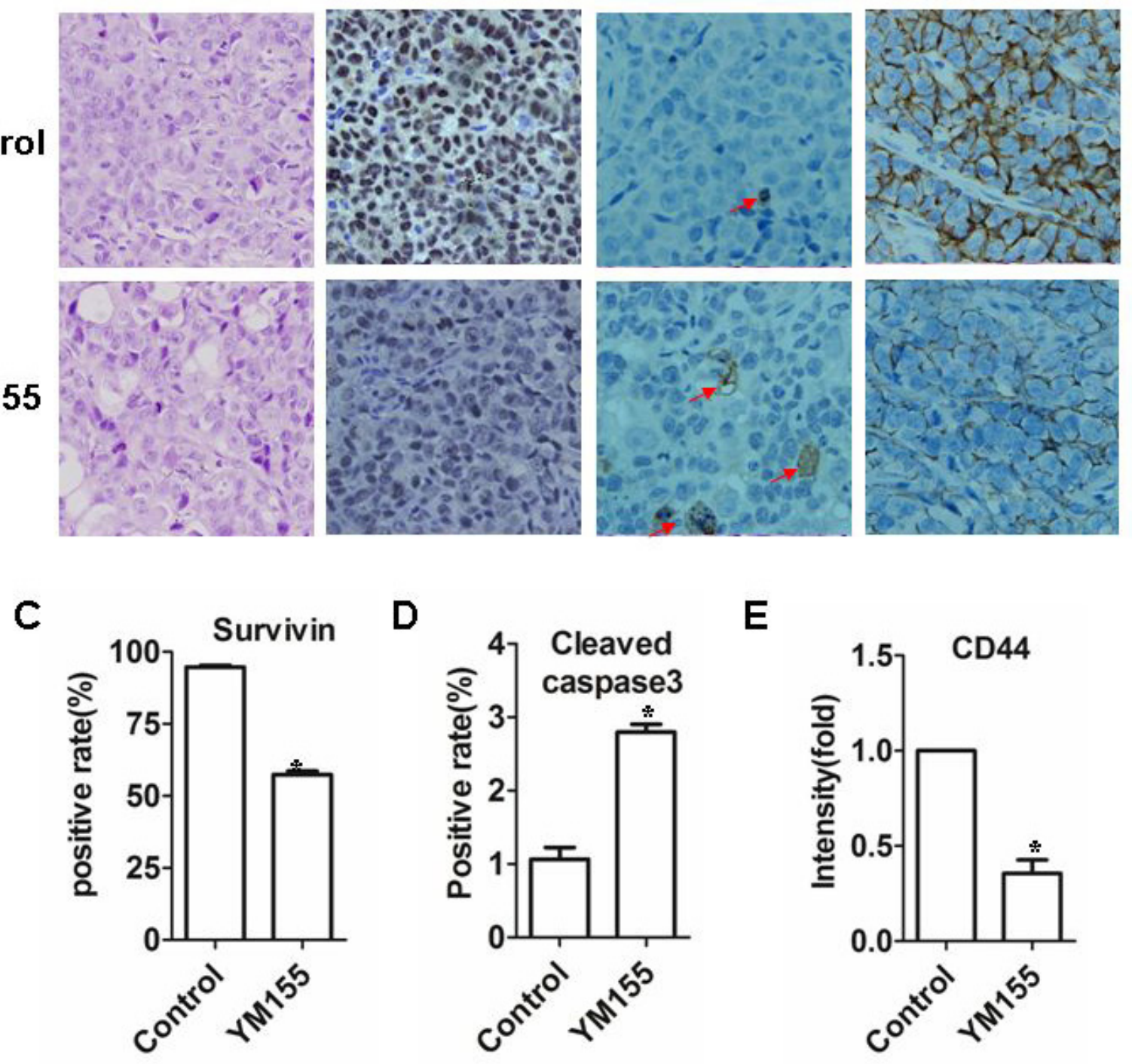

Figure 6: YM155 induces apoptosis and inhibits gastric CSCs in vivo. A. YM155 treatment decreased protein levels of survivin and CD44. Xenograft tumor tissues (from Figure 5) were extracted and protein concentrations were measured. The levels of protein were determined by Western blot (left panel). The data of the densities presented are means \pm SD of 3 mice. B. YM155 treatment inhibits expression of surviving, cleaved caspase-3 and CD44. Tissue sections were subjected to surviving, cleaved caspase-3 and CD44 immunostaining. Representative photos were shown (Original magnification $\times 400$ ). C.-D. Quantification analysis of survivin and cleaved caspase 3 positive staining cells. Data presented are means \pm SD of 7 mice. ${ }^{*} p<0.01$, compared to control treatment. E. Quantification analysis of intensities of CD44 positive staining cells. Data presented are means $\pm \mathrm{SD}$ of five mice. ${ }^{*} p<0.01$, compared to control treatment. 
Control

\section{Heart}
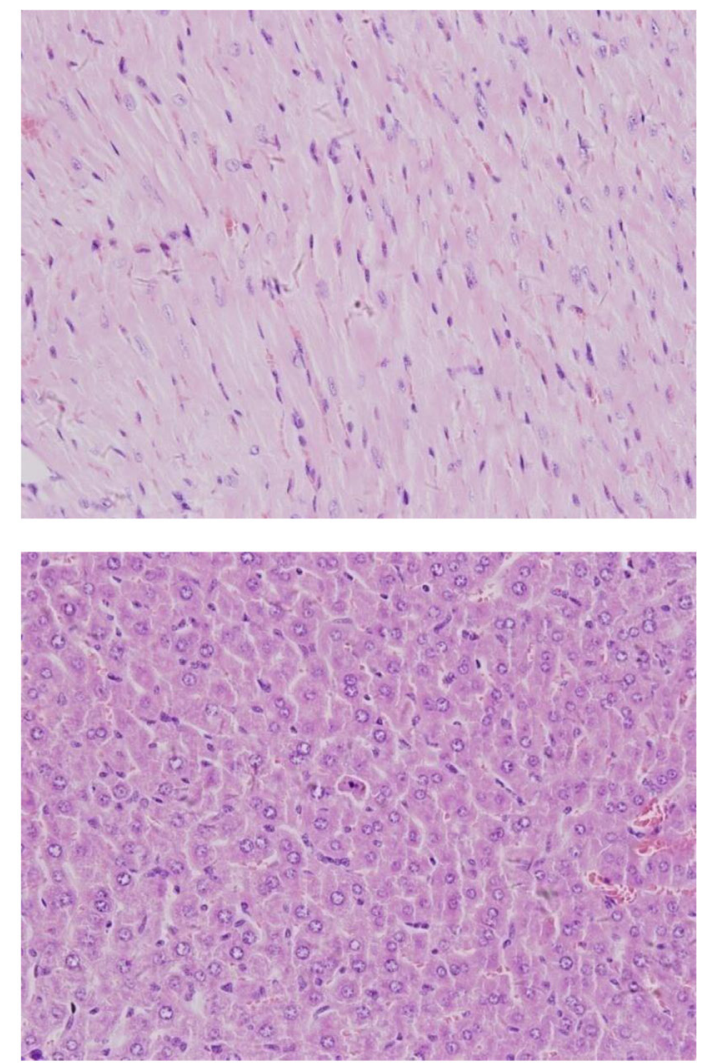

Liver

\section{Lung}
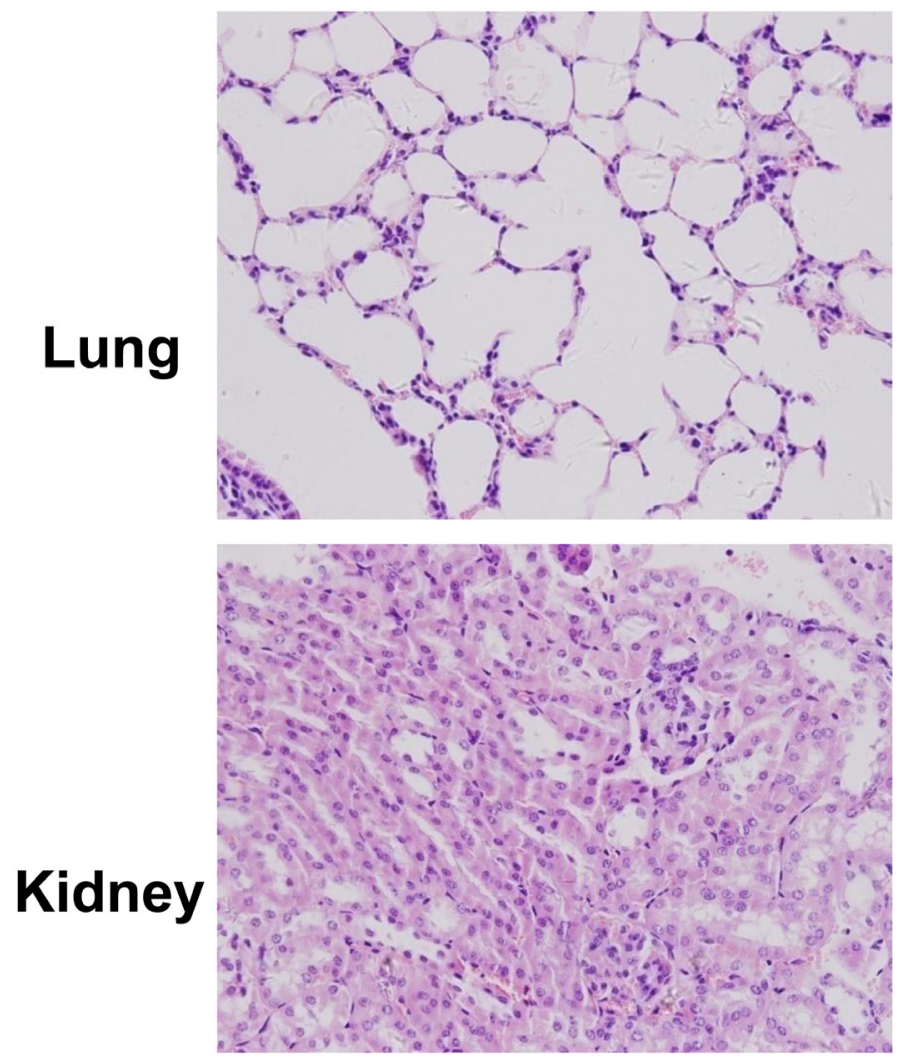

YM155
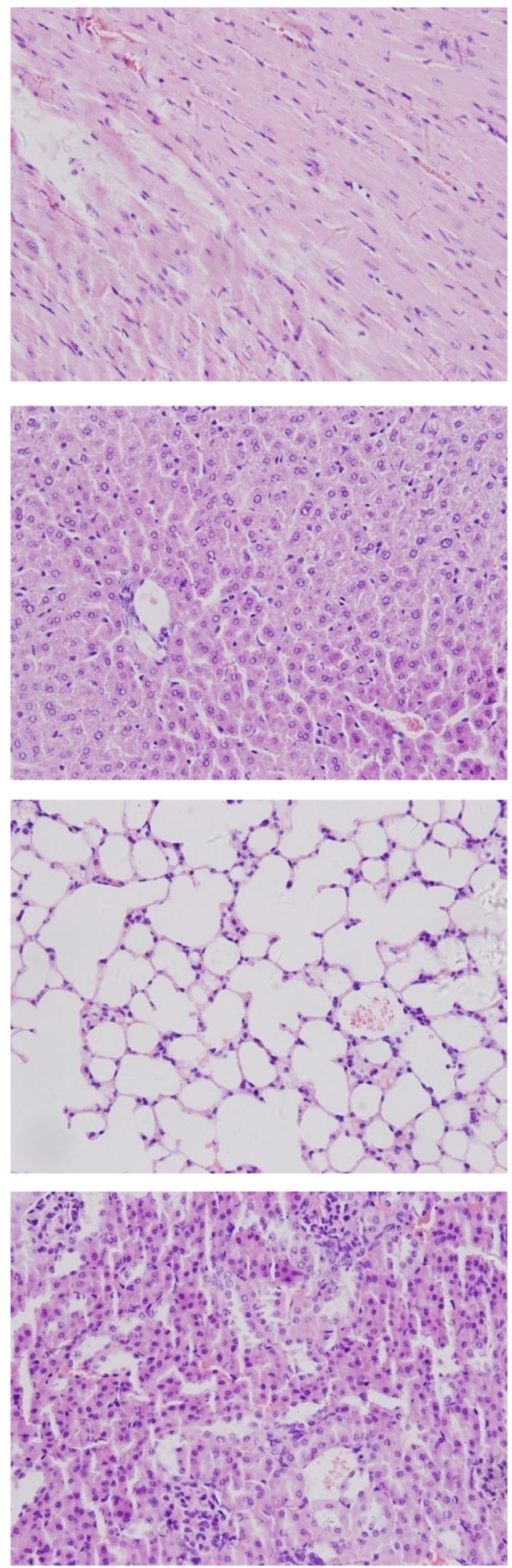

Figure 7: YM155 treatment does not cause histopathological alteration of organs. Main organs (heart, liver, lung and kidney) of mice treated with YM155 or control vehicle were subjected to H\&E staining. Histology analysis (heart, liver, lung and kidney) were conducted by pathologist. Representative photos were shown (Original magnification $\times 400$ ). 
suppressant [24], induced apoptosis of gastric cancer cells, inhibited expansion of gastric CSCs and reduced expression of CSC molecules (CD44 and $\beta$-catanin) and suppressed gastric cancer xenograft growth. Our results, for the first time, demonstrate that YM155 inhibit gastric cancer growth by inhibition CSCs and document a new mechanism that YM155 inhibits tumor growth.

Our previous studies have demonstrated that inhibition of survivin function by AAV-mediated survivin mutant or inhibition of survivin expression by antisense oligonucleotide suppress gastric and colon cancer growth $[37,38]$. Although AAV vector can efficaciously mediated long-term expression of survivin mutant, its safety and inconvenience are still the obstacles for its clinical use. YM155 is a small imidazolium-based molecule that inhibits specifically both mRNA and protein expression of survivin [24] . YM155 has been demonstrated to suppress the growth of a large number of human cancers including non-small-cell lung cancer, breast cancer, hormonerefractory prostate cancer, ovarian cancer, leukemia, nonHodgkin's lymphoma, sarcoma, melanoma, esophageal cancer, renal cancer, breast cancer, hepatoma [24, 3942]. The combination of YM155 and chemotherapeutic drugs (including etoposide, platinum, doxetaxel) enhanced inhibition of survivin expression, resulting in stronger inhibition of tumor growth in some cancer types such as non-small cell lung cancer, melanoma and neuroblastoma. The mean log growth inhibition of $50 \%$ (GI50) value was around $15 \mathrm{nM}$ for YM155 [43-45]. In this study, we have demonstrated the potent anti-proliferation activity of YM155 to gastric cancer cells with the mean IC50 of YM155 was 11.6 13.2 nM. The data suggest that gastric cancer cells are also sensitive to YM155. Furthermore, we showed that YM155 significantly inhibited gastric xenograft tumor growth in a nude mouse model and reduced tumor weight, exhibiting strong anti-tumor effect. Our results demonstrated that survivin inhibitor, YM155, is able to inhibit gastric cancer growth.

Survivin has been demonstrated to inhibit caspase 9 and caspase 3, resulting in inhibition intrinsic apoptosis pathway [46]. Previous studies have suggested that YM155 specifically down regulates survivin expression in prostate cancer cells and non-small cell lung cancer (NSCLC) cells without affecting other proteins [23, 47]. Our results showed that YM155 downregulated survivin expression without affecting XIAP and induced cleavage of caspase 3, caspase 9 and caspase 8. Furthermore, the inhibitors of caspases 9 and caspase 8 significantly suppressed YM155-induced apoptosis, suggesting that YM155 induces apoptosis by activating intrinsic and extrinsic apoptotic pathway. A study showed that YM155 not only inhibits survivin, but also regulate expression of a large number of genes including in death receptor signaling and TNFR1 signaling that induce apoptosis through a extrinsic apoptosis pathway [48], consistent with our results.
While YM155 is originally identified as a survivin inhibitor, its mechanisms of antitumor actions are not fully understood. Recently, a number of studies have shown that YM155 could inhibit expression of EGFR, XIAP, Mcl1 [49-51], suggesting that YM155 function is beyond to inhibition of survivin. We found that YM155 could inhibit expansion of gastric CSCs. CSCs are a subpopulation in tumors that have features to initiate tumor growth, sustain tumor self-renewal, promote relapse and metastasis by giving rise to new tumors [52]. However, the roles of CSCs in tumorigenesis remain in debate $[53,54]$. Survivin is highly expressed in colon CSCs [11] and is upregulated by interleukin-4 [55]. Mutant APC up-regulates survivin, causing apoptosis inhibition and the expansion of colon tissue stem cells in the colon crypt, thereby initiating tumorigenesis $[14,15]$. Survivin has been shown to be overexpressed in AML stem/progenitor cells [16]. The data suggested that survivin plays a role in regulation of CSCs. It is well known that Wnt/ $\beta$-catenin signaling is essential for expansion of CSCs [12, 13]. Survivin has been shown to be a downstream gene of Wnt signaling pathway [11]. Therefore, survivin is a potential targeting for inhibition of CSCs. In this study, we observed that YM155 markedly suppressed formation and expansion of spheres in gastric cancer cells and downregulated expression of $\beta$-catenin, c-Myc and Cyclin D1, which are downstream genes of $\mathrm{Wnt} / \beta$-catenin signaling. More importantly, YM155 inhibited CD44 expression in gastric cancer cells and gastric cancer tissues both in vitro and in vivo. $\mathrm{CD}_{4} 4^{+}$gastric cancer cells is a CSC marker of human gastric cancer and have stronger tumorigenic than CD44- gastric cancer cells $[17,18]$. Our results, for the first time, show that YM155 inhibits gastric tumor growth by inhibition of expansion of CD $44^{+}$gastric CSCs.

YM155 has been studied in clinical trial in several cancer types. In phase I and II studies, YM155 has shown to be safe and well-tolerated, with a maximum tolerated dose of $8.0 \mathrm{mg} / \mathrm{m}^{2} / \mathrm{d}$. In our xenograft mouse model, a 7 -day continuous infusion of YM155 at $5 \mathrm{mg} / \mathrm{kg}$ induced massive tumor regression with decreased expression of survivin and CD44 in intratumoral. Furthermore, we did not observe serious side effects in some organisms. The data document that YM155 is a safety and promising agent for gastric cancer therapy.

\section{MATERIALS AND METHODS}

\section{Cell lines and regents}

The human gastric cancer cell lines SGC-7901, MKN28 and AGS were maintained in RPMI1640 (Thermo Scientific, China) supplemented with 10\% fetal bovine serum (Life Technologies inc., Grand island, USA), 100 $\mathrm{U} / \mathrm{ml}$ of penicillin sodium, and $100 \mathrm{mg} / \mathrm{ml}$ of streptomycin 
sulfate at $37^{\circ} \mathrm{C}$ in a humidified air atmosphere containing 5\% CO2. YM155 monobromide (YM155) was purchased from ChemieTek Company (Indianapolis, USA).

\section{MTT assay}

In vitro cell proliferation was measured using MTT assay. Cells in the logarithmic phase of growth were seeded into 96 -well culture plates at $1 \times 10^{4}$ cells per well for 24 hours. After treatment with different concentrations of YM155 or vehicle control for 48 hours, $100 \mu$ l of MTT solution $(1 \mathrm{mg} / \mathrm{ml})$ were added to each well, and the cells were further incubated at $37{ }^{\circ} \mathrm{C}$ for 4 hours. The supernatant was replaced with dimethyl sulfoxide (DMSO) to dissolve formazan production. The absorbance at wave length $595 \mathrm{~nm}$ was measured using micro-ELISA reader (Bio-Rad, Hercules, CA). The mean 50\% growth inhibition (IC50) value was calculated by logistic analysis. The mean IC50 value was obtained from the results of 3 independent assays.

\section{Soft agar colony formation assay}

Anchorage-independent cell growth was determined by soft agar clone formation assay. Cells $\left(5 \times 10^{2}\right)$ in 0.5 $\mathrm{ml}$ complete culture medium containing $0.3 \%$ agar and YM155 or vehicle were cultured on the top of $0.7 \%$ agar in the same medium. Dishes were then transferred into culture incubator. Cultures were stained with $0.1 \%$ crystal violet at 16 days, colonies were counted under microscope (magnification $50 \times$ ). Colonies containing $\geq 50$ cells were considered viable.

\section{Flow cytometry assay for apoptosis}

Cells were collected and washed with cold PBS, then stained with FITC Annexin V/PI (BD Biosciences, San Diego, USA ) according to production manuals. Apoptotic cells were analyzed by flow cytometry (Coulter, Luton, United Kingdom).

\section{Western blot analysis}

Cells were lysed in lysis buffer (1X PBS, $1 \%$ NP40,0.1\% SDS, $5 \mathrm{mM} \quad$ EDTA, $0.5 \%$ sodium deoxyccholate, $1 \mathrm{mM}$ sodium orthovanadate, and 1 $\mathrm{mM}$ phenylmethylsulfonyl fluoride). Protein samples were electrophoresed in $10 \%$ denaturing sodium dodecylsulfate polyacrylamide gel, and transferred to Immobilon-P transfer membrane (Millipore, Billerica, MA). The blots were incubated with specific primary antibodies, reacted with a peroxidase-conjugated second antibody (Cell Signaling Technology, Inc., Danvers, USA) and then visualized by chemiluminescence HRP
Substrate (Millipore, Billerica, MA). Survivin (71G4B7), PARP, Caspase 3/9/7, cleaved caspase- $8, \beta$-catenin, c-Myc, Cyclin D1, CD44 antibodies were all purchased from Cell Signaling, (Cell Signaling Technology, Inc., Danvers, USA) and $\beta$-actin antibody was from Santa Cruz Biotechnology (Santa Cruz, California).

\section{Polymerase chain reaction (PCR)}

Total RNA from cultured cells was prepared with RNAprep pure cell kit (Tiangen). First-strand cDNA was synthesized with oligo (dT) primer by using PrimeScript $^{\circledR}$ RT reagent Kit (Takara, Daliang, China). Primer sequences were designed using the Primer Quest $^{\mathrm{SM}}$ and were as follows: human survivin (forward) 5-ATGGGTGCCCCGACGTTGCC-3 and (reverse) 5-TCAATCCATGGCAGCCAG CT-3; human CD44 (forward) 5-AAAGCAGGACCTTCATCCCAGTGA-3 and (reverse) 5-TTGCTCCACCTTCTTGACTCCCAT-3; human GAPDH (forward) GAAGACTGTGGATGGCCCCT and (reverse) GTCCACCACCCTGTTGCTGT. PCR was performed using the PCR Master Mix (Tiangen, China), according to the manufacturer's instructions.

\section{In situ detection of apoptotic cells by TUNEL assay}

Cells were harvested and fixed by $0.4 \%$ paraformaldehyde, TUNEL staining was carried out using In Situ Cell Death Detection Kit (Roche, Indianapolis, USA) according to the manufactory manuals. Apoptotic cells show strong nuclear green fluorescence. The apoptotic cells were counted in 5 randomly selected fields viewed at $\times 20$ magnification. The apoptotic index was calculated as the number of apoptotic cells/total number of nucleated cells $\times 100 \%$.

\section{Spheroid colony formation assay}

Gastric cancer cells $\left(10^{2}\right.$ cells per well $)$ were inoculated in a ultra-low-attachment 96-well plates (Corning, USA) supplemented with $200 \mu 1$ of RPMI-1640 medium (Thermo Scientific, China) plus $0.3 \%$ albumin from bovine serum (BSA, Sigma-Alorich, USA), $20 \mathrm{ng} /$ $\mathrm{ml}$ human recombinant epidermal growth factor (EGF, Invitrogen Corp., Frederick, MD, USA) and $10 \mathrm{ng} / \mathrm{ml}$ human recombinant basic fibroblast growth factor (bFGF, Invitrogen Corp., Frederick, MD, USA). Two weeks after culture, each well was examined under light microscope and the total spheroid colonies numbers per well were counted. The rates of sphere formation were calculated as the number of apoptotic cells/total number of nucleated cells $1 \times 100 \%$. 


\section{Gastric cancer xenograft experiment}

Five weeks old female BALB/c nude mice were purchased from Shanghai Experimental Animals Centre of Chinese Academy of Sciences. All animal studies abode the rules of The Laboratory Animal Ethics Committee of Renji Hospital, Shanghai Jiaotong University School of Medicine. Xenografts were established by s.c. injection of SGC 7901 cells into the right flanks of the mice $\left(5 \times 10^{6}\right.$ $/ 0.1 \mathrm{ml}$ per mouse. After one week, tumor size reached approximately $80 \mathrm{~mm}^{3}-100 \mathrm{~mm}^{3}$, mice were randomly assigned to treatment and control groups. YM155 at 5mg/ $\mathrm{kg} /$ day or vehicle control was administered subcutaneously as a 7-day continuous infusion using a micro-osmotic pump (Alzet model 1007D) implanted in the left dorsal flank under anesthesia. Body weight of mice was assessed twice weekly, and tumor diameter was measured using standard calipers. After two weeks observation, mice were sacrificed and tumors were weighed, subsequently processed for immunohistochemistry and Western Blot.

\section{Immunohistochemistry}

The expression of survivin, CD44, cleavedcaspase-3 in tumor tissues was detected with the UltraSensitive ${ }^{\mathrm{TM}} \mathrm{S}-\mathrm{P}$ (Mouse/Rabbit) kit (Maxin-Bio, China) according to the manufacturer instructions. Briefly, sections were dewaxed in xylene. Antigen retrieval was performed with a microwave for $10 \mathrm{~min}$ at $100{ }^{\circ} \mathrm{C}$. The sections were then incubated with rabbit anti-survivin antibody (1:200), anti-CD44 antibody (1:50), anticleaved-caspase-3 antibody (1:100) (cell signaling) for 1 hour, followed by biotinylated anti-IgG Antibody and streptavidin-biotinylated-complex horseradish peroxidase. Antibody binding was visualized by incubated with DAB (Maxin-Bio, China).Sections were then stained with hematoxylin.

\section{Statistical analysis}

Data were expressed as the means of at least three different experiments $\pm \mathrm{SD}$. The results were analyzed by ONE-WAY ANOVA, and $P \leq 0.05$ was considered statistically significant.

\section{ACKNOWLEDGMENTS}

The project was supported by NSFC 8117259 , NSFC 81272403, NSFC 81472727, NSFC 91029718, NSFC 91429307; Key Discipline and Specialty Foundation of Shanghai Municipal Commission of Health and Family Planning; Science and Technology Commission of Shanghai Municipality (15JC1403100).

\section{CONFLICTS OF INTEREST}

No potential conflicts of interest.

\section{REFERENCES}

1. Smith MG, Hold GL, Tahara E and El-Omar EM. Cellular and molecular aspects of gastric cancer. World J Gastroenterol. 2006; 12:2979-2990.

2. Ambrosini G, Adida C and Altieri DC. A novel antiapoptosis gene, survivin, expressed in cancer and lymphoma. Nat Med. 1997; 3:917-921.

3. Giodini A, Kallio MJ, Wall NR, Gorbsky GJ, Tognin S, Marchisio PC, Symons M and Altieri DC. Regulation of microtubule stability and mitotic progression by survivin. Cancer Res. 2002; 62:2462-2467.

4. Tamm I, Wang Y, Sausville E, Scudiero DA, Vigna N, Oltersdorf T and Reed JC. IAP-family protein survivin inhibits caspase activity and apoptosis induced by Fas (CD95), Bax, caspases, and anticancer drugs. Cancer Res. $1998 ; 58: 5315-5320$

5. Lu CD, Altieri DC and Tanigawa N. Expression of a novel antiapoptosis gene, survivin, correlated with tumor cell apoptosis and p53 accumulation in gastric carcinomas. Cancer Res. 1998; 58:1808-1812.

6. Okada E, Murai Y, Matsui K, Isizawa S, Cheng C, Masuda $\mathrm{M}$ and Takano Y. Survivin expression in tumor cell nuclei is predictive of a favorable prognosis in gastric cancer patients. Cancer letters. 2001; 163:109-116.

7. Liu JL, Gao W, Kang QM, Zhang XJ and Yang SG. Prognostic value of survivin in patients with gastric cancer: a systematic review with meta-analysis. PLoS One. 2013; 8:e71930.

8. Ikeguchi M, Liu J and Kaibara N. Expression of survivin mRNA and protein in gastric cancer cell line (MKN-45) during cisplatin treatment. Apoptosis. 2002; 7:23-29.

9. Zheng WE, Chen H, Yuan SF, Wu LL, Zhang W, Sun HY and Chen WJ. Overexpression of betaIII-tubulin and survivin associated with drug resistance to docetaxel-based chemotherapy in advanced gastric cancer. J BUON. 2012; $17: 284-290$

10. Shen X, Zheng JY, Shi H, Zhang Z and Wang WZ. Survivin knockdown enhances gastric cancer cell sensitivity to radiation and chemotherapy in vitro and in nude mice. Am J Med Sci. 2012; 344:52-58.

11. Vermeulen L, De Sousa EMF, van der Heijden M, Cameron K, de Jong JH, Borovski T, Tuynman JB, Todaro M, Merz C, Rodermond H, Sprick MR, Kemper K, Richel DJ, Stassi $\mathrm{G}$ and Medema JP. Wnt activity defines colon cancer stem cells and is regulated by the microenvironment. Nat Cell Biol. 2010; 12:468-476.

12. Mao J, Fan S, Ma W, Fan P, Wang B, Zhang J, Wang H, Tang B, Zhang Q, Yu X, Wang L, Song B and Li L. Roles of Wnt/beta-catenin signaling in the gastric cancer stem 
cells proliferation and salinomycin treatment. Cell Death Dis. 2014; 5:e1039.

13. Cai $\mathrm{C}$ and Zhu $\mathrm{X}$. The Wnt/beta-catenin pathway regulates self-renewal of cancer stem-like cells in human gastric cancer. Mol Med Rep. 2012; 5:1191-1196.

14. Zhang T, Otevrel T, Gao Z, Ehrlich SM, Fields JZ and Boman BM. Evidence that APC regulates survivin expression: a possible mechanism contributing to the stem cell origin of colon cancer. Cancer Res. 2001; 61:86648667.

15. Zhang T, Fields JZ, Opdenaker L, Otevrel T, Masuda E, Palazzo JP, Isenberg GA, Goldstein SD, Brand M and Boman BM. Survivin-induced Aurora-B kinase activation: A mechanism by which APC mutations contribute to increased mitoses during colon cancer development. Am J Pathol. 2010; 177:2816-2826.

16. Carter BZ, Qiu Y, Huang X, Diao L, Zhang N, Coombes KR, Mak DH, Konopleva M, Cortes J, Kantarjian HM, Mills GB, Andreeff M and Kornblau SM. Survivin is highly expressed in CD34(+)38(-) leukemic stem/progenitor cells and predicts poor clinical outcomes in AML. Blood. 2012; 120:173-180.

17. Takaishi S, Okumura T, Tu S, Wang SS, Shibata W, Vigneshwaran R, Gordon SA, Shimada Y and Wang TC. Identification of gastric cancer stem cells using the cell surface marker CD44. Stem Cells. 2009; 27:1006-1020.

18. Chen W, Zhang X, Chu C, Cheung WL, Ng L, Lam S, Chow A, Lau T, Chen M, Li Y, Nie Y, Wong BC and Pang R. Identification of CD44+ cancer stem cells in human gastric cancer. Hepatogastroenterology. 2013; 60:949-954.

19. Pennati M, Folini M and Zaffaroni N. Targeting survivin in cancer therapy. Expert Opin Ther Targets. 2008; 12:463476.

20. Chen $T$ and Deng C. Inhibitory effect of siRNA targeting survivin in gastric cancer MGC-803 cells. Int Immunopharmacol. 2008; 8:1006-1011.

21. Li YH, Chen M, Zhang M, Zhang XQ, Zhang S, Yu CG, $\mathrm{Xu} \mathrm{ZM}$ and Zou XP. Inhibitory effect of survivin-targeting small interfering RNA on gastric cancer cells. Genet Mol Res. 2014; 13:6786-6803.

22. Tu SP, Jiang XH, Lin MC, Cui JT, Yang Y, Lum CT, Zou B, Zhu YB, Jiang SH, Wong WM, Chan AO, Yuen MF, Lam SK, Kung HF and Wong BC. Suppression of survivin expression inhibits in vivo tumorigenicity and angiogenesis in gastric cancer. Cancer Res. 2003; 63:7724-7732.

23. Nakahara T, Kita A, Yamanaka K, Mori M, Amino N, Takeuchi M, Tominaga F, Hatakeyama S, Kinoyama I, Matsuhisa A, Kudoh M and Sasamata M. YM155, a novel small-molecule survivin suppressant, induces regression of established human hormone-refractory prostate tumor xenografts. Cancer Res. 2007; 67:8014-8021.

24. Nakahara T, Kita A, Yamanaka K, Mori M, Amino N, Takeuchi M, Tominaga F, Kinoyama I, Matsuhisa A, Kudou M and Sasamata M. Broad spectrum and potent antitumor activities of YM155, a novel small-molecule survivin suppressant, in a wide variety of human cancer cell lines and xenograft models. Cancer Sci. 2011; 102:614-621.

25. Tolcher AW, Mita A, Lewis LD, Garrett CR, Till E, Daud AI, Patnaik A, Papadopoulos K, Takimoto C, Bartels P, Keating A and Antonia S. Phase I and pharmacokinetic study of YM155, a small-molecule inhibitor of survivin. J Clin Oncol. 2008; 26:5198-5203.

26. Cheson BD, Bartlett NL, Vose JM, Lopez-Hernandez A, Seiz AL, Keating AT, Shamsili S and Papadopoulos KP. A phase II study of the survivin suppressant YM155 in patients with refractory diffuse large B-cell lymphoma. Cancer. 2012; 118:3128-3134.

27. Satoh T, Okamoto I, Miyazaki M, Morinaga R, Tsuya A, Hasegawa Y, Terashima M, Ueda S, Fukuoka M, Ariyoshi Y, Saito T, Masuda N, Watanabe H, Taguchi T, Kakihara T, Aoyama Y, et al. Phase I study of YM155, a novel survivin suppressant, in patients with advanced solid tumors. Clin Cancer Res. 2009; 15:3872-3880.

28. Lewis KD, Samlowski W, Ward J, Catlett J, Cranmer L, Kirkwood J, Lawson D, Whitman E and Gonzalez R. A multi-center phase II evaluation of the small molecule survivin suppressor YM155 in patients with unresectable stage III or IV melanoma. Invest New Drugs. 2011; 29:161166.

29. Kelly RJ, Thomas A, Rajan A, Chun G, Lopez-Chavez A, Szabo E, Spencer S, Carter CA, Guha U, Khozin S, Poondru S, Van Sant C, Keating A, Steinberg SM, Figg $\mathrm{W}$ and Giaccone G. A phase I/II study of sepantronium bromide (YM155, survivin suppressor) with paclitaxel and carboplatin in patients with advanced non-small-cell lung cancer. Ann Oncol. 2013; 24:2601-2606.

30. O'Brien CA, Pollett A, Gallinger S and Dick JE. A human colon cancer cell capable of initiating tumour growth in immunodeficient mice. Nature. 2007; 445:106-110.

31. Sharpe B, Beresford M, Bowen R, Mitchard J and Chalmers AD. Searching for prostate cancer stem cells: markers and methods. Stem Cell Rev. 2013; 9:721-730.

32. Vermeulen L, Sprick MR, Kemper K, Stassi G and Medema JP. Cancer stem cells — old concepts, new insights. Cell Death Differ. 2008; 15:947-958.

33. Zhang C, Li C, He F, Cai Y and Yang H. Identification of CD44+CD24+ gastric cancer stem cells. J Cancer Res Clin Oncol. 2011; 137:1679-1686.

34. Krieg A, Baseras B, Tomczak M, Verde PE, Stoecklein $\mathrm{NH}$ and Knoefel WT. Role of survivin as prognostic and clinicopathological marker in gastric cancer: a metaanalysis. Mol Biol Rep. 2013; 40:5501-5511.

35. Chen J, Li T, Liu Q, Jiao H, Yang W, Liu X and Huo Z. Clinical and prognostic significance of HIF-1alpha, PTEN, CD44v6, and survivin for gastric cancer: a meta-analysis. PLoS One. 2014; 9:e91842.

36. Wenying Z, Zhaoning J, Zhimin Y, Dongyun C and Lili S. Survivin siRNA inhibits gastric cancer in nude mice. Cell 
Biochem Biophys. 2012; 62:337-341.

37. Chiou SK, Hoa N, Hodges A, Ge L and Jadus MR. Indomethacin promotes apoptosis in gastric cancer cells through concomitant degradation of Survivin and Aurora B kinase proteins. Apoptosis. 2014; 19:1378-1388.

38. Tu SP, Cui JT, Liston P, Huajiang X, Xu R, Lin MC, Zhu YB, Zou B, Ng SS, Jiang SH, Xia HH, Wong WM, Chan AO, Yuen MF, Lam SK, Kung HF, et al. Gene therapy for colon cancer by adeno-associated viral vector-mediated transfer of survivin Cys84Ala mutant. Gastroenterology. 2005; 128:361-375.

39. Zhao N, Mao Y, Han G, Ju Q, Zhou L, Liu F, Xu Y and Zhao X. YM155, a survivin suppressant, triggers PARPdependent cell death (parthanatos) and inhibits esophageal squamous-cell carcinoma xenografts in mice. Oncotarget. 2015; 6:18445-18459. doi: 10.18632/oncotarget.4315.

40. Guo K, Huang P, Xu N, Xu P, Kaku H, Zheng S, Xu A, Matsuura E, Liu C and Kumon H. A combination of YM-155, a small molecule survivin inhibitor, and IL-2 potently suppresses renal cell carcinoma in murine model. Oncotarget. 2015; 6:21137-21147. doi: 10.18632/ oncotarget.4121.

41. Vequaud E, Seveno C, Loussouarn D, Engelhart L, Campone M, Juin P and Barille-Nion S. YM155 potently triggers cell death in breast cancer cells through an autophagy-NF-kB network. Oncotarget. 2015; 6:1347613486. doi: 10.18632/oncotarget.3638.

42. Xia H, Chen J, Shi M, Deivasigamani A, Ooi LL and Hui KM. The over-expression of survivin enhances the chemotherapeutic efficacy of YM155 in human hepatocellular carcinoma. Oncotarget. 2015; 6:5990-6000. doi: 10.18632/oncotarget.3337.

43. Iwasa T, Okamoto I, Takezawa K, Yamanaka K, Nakahara T, Kita A, Koutoku H, Sasamata M, Hatashita E, Yamada Y, Kuwata K, Fukuoka M and Nakagawa K. Marked antitumour activity of the combination of YM155, a novel survivin suppressant, and platinum-based drugs. $\mathrm{Br} \mathrm{J}$ Cancer. 2010; 103:36-42.

44. Yamanaka K, Nakahara T, Yamauchi T, Kita A, Takeuchi M, Kiyonaga F, Kaneko N and Sasamata M. Antitumor activity of YM155, a selective small-molecule survivin suppressant, alone and in combination with docetaxel in human malignant melanoma models. Clin Cancer Res. $2011 ; 17: 5423-5431$

45. Clemens MR, Gladkov OA, Gartner E, Vladimirov V, Crown J, Steinberg J, Jie F and Keating A. Phase II, multicenter, open-label, randomized study of YM155 plus docetaxel as first-line treatment in patients with HER2negative metastatic breast cancer. Breast Cancer Res Treat. 2015; 149:171-179.

46. Yamanaka K, Nakata M, Kaneko N, Fushiki H, Kita A, Nakahara T, Koutoku H and Sasamata M. YM155, a selective survivin suppressant, inhibits tumor spread and prolongs survival in a spontaneous metastatic model of human triple negative breast cancer. Int J Oncol. 2011;
39:569-575.

47. Iwasa T, Okamoto I, Suzuki M, Nakahara T, Yamanaka K, Hatashita E, Yamada Y, Fukuoka M, Ono K and Nakagawa K. Radiosensitizing effect of YM155, a novel small-molecule survivin suppressant, in non-small cell lung cancer cell lines. Clin Cancer Res. 2008; 14:6496-6504.

48. Tao YF, Lu J, Du XJ, Sun LC, Zhao X, Peng L, Cao L, Xiao PF, Pang L, Wu D, Wang N, Feng X, Li YH, Ni J, Wang $\mathrm{J}$ and Pan J. Survivin selective inhibitor YM155 induce apoptosis in SK-NEP-1 Wilms tumor cells. BMC Cancer. 2012; $12: 619$.

49. Na YS, Yang SJ, Kim SM, Jung KA, Moon JH, Shin JS, Yoon DH, Hong YS, Ryu MH, Lee JL, Lee JS and Kim TW. YM155 induces EGFR suppression in pancreatic cancer cells. PLoS One. 2012; 7:e38625.

50. Cheng SM, Chang YC, Liu CY, Lee JY, Chan HH, Kuo CW, Lin KY, Tsai SL, Chen SH, Li CF, Leung E, Kanwar JR, Huang CC, Chang JY and Cheung CH. YM155 downregulates survivin and XIAP, modulates autophagy and induces autophagy-dependent DNA damage in breast cancer cells. Br J Pharmacol. 2015; 172:214-234.

51. Wagner V, Hose D, Seckinger A, Weiz L, Meissner T, Reme T, Breitkreutz I, Podar K, Ho AD, Goldschmidt H, Kramer A, Klein B and Raab MS. Preclinical efficacy of sepantronium bromide (YM155) in multiple myeloma is conferred by down regulation of Mcl-1. Oncotarget. 2014; 5:10237-10250. doi: 10.18632/oncotarget.2529.

52. Wei B, Chen L, Li R and Tian J. Stem cells in gastrointestinal cancers: a matter of choice in cell fate determination. Expert Rev Anticancer Ther. 2010; 10:16211633.

53. Blagosklonny MV. Cancer stem cell and cancer stemloids: from biology to therapy. Cancer Biol Ther. 2007; 6:16841690.

54. Blagosklonny MV. Target for cancer therapy: proliferating cells or stem cells. Leukemia. 2006; 20:385-391.

55. Waclawczyk S, Buchheiser A, Flogel U, Radke TF and Kogler G. In vitro differentiation of unrestricted somatic stem cells into functional hepatic-like cells displaying a hepatocyte-like glucose metabolism. J Cell Physiol. 2010; 225:545-554. 